\title{
Inhibition of Voltage-Gated K Channels in Synaptosomes by sn-1,2-Dioctanoylglycerol, an Activator of Protein Kinase C
}

\author{
Kathryn A. Colby ${ }^{1}$ and Mordecai P. Blaustein ${ }^{1.2}$ \\ Departments of 'Physiology and 2 Medicine, University of Maryland School of Medicine, Baltimore, Maryland 21201
}

Tracer efflux studies were used to determine the effect of activation of protein kinase $\mathbf{C}$ on $\mathbf{K}$ channel function in rat brain synaptosomes. Hippocampal synaptosomes were treated with sn-1,2-dioctanoylglycerol (diC8), a synthetic diacylglycerol (DG) analog that activates protein kinase $\mathrm{C}$. Dic8 inhibited depolarization-induced ${ }^{86} \mathrm{Rb}$ efflux through voltage-gated $K$ channels but did not affect the component of efflux corresponding to $\mathrm{Ca}$-activated $\mathrm{K}$ channels. In timecourse experiments, diC8 inhibited two components of ${ }^{86} \mathrm{Rb}$ efflux: efflux through a rapidly inactivating, voltage-gated $K$ channel (responsible for the " $A$ " current) and that through a slowly inactivating, voltage-gated $\mathrm{K}$ channel (believed to be the 'delayed rectifier'). Experiments with specific blockers of these voltage-gated $K$ channels supported this observation. Inhibition of K-stimulated ${ }^{86} \mathrm{Rb}$ efflux by $\mathrm{diC} 8$ was time dependent: at least 15 sec of preincubation was required before the effect could be observed. The effect of diC8 was concentration dependent: $50 \mu \mathrm{M}$ diC 8 produced a half-maximal inhibition of K-stimulated ${ }^{86} \mathbf{R b}$ efflux.

The idea that the inhibition of synaptosome $K$ channels by diC8 resulted from activation of $C$ kinase was supported by pharmacological evidence. The action of dic8 was mimicked by 1-oleoyl-2-acetylglycerol, another DG analog that activates protein kinase $\mathrm{C}$, but not by deoxy-diC8, a DG analog that does not activate $C$ kinase. Inhibition of $C$ kinase by sphingosine or $\mathrm{H}-7$ prevented the diC8 effect.

These studies demonstrate that synaptosomes are a good model in which to study modulation of mammalian CNS K channels. The data suggest that protein kinase $C$ plays an important role in the regulation of the activity of some types of $K$ channels. Modulation of $K$ channel activity may, in turn, regulate the release of neurotransmitter from the presynaptic terminal.

Potassium $(\mathrm{K})$ channels located in the presynaptic terminal control excitability and neurotransmitter release and thus have the potential to be key regulators of synaptic transmission. Previous work from our laboratory has shown that isolated nerve terminals (synaptosomes) contain a variety of $\mathrm{K}$ channels that can

Received Feb. 19, 1988; revised May 9, 1988; accepted May 11, 1988.

This work was supported by NIH Grant NS-16106 to M.P.B. We thank Drs. B. E. Alger, M. K. Selmanoff, R. G. Sorensen, and Ms. M. J. Schneider for critical reading of the manuscript, and Ms. M. E. Davis for helpful discussions upon the initiation of these studies. We are grateful to Dr. R. M. Bell for generous donation of deoxy-diC8.

Correspondence should be addressed to Dr. Mordecai P. Blaustein, Department of Physiology, University of Maryland School of Medicine, 655 West Baltimore Street, Baltimore, MD 21201.

Copyright (C) 1988 Society for Neuroscience $0270-6474 / 88 / 124685-08 \$ 02.00 / 0$ be studied with ${ }^{86} \mathrm{Rb}$ efflux methods. The various $\mathrm{K}$ channels can be distinguished on the basis of their kinetic and pharmacological characteristics (Bartschat and Blaustein, 1985a, b; Benishin et al., 1987; Blaustein et al., 1988) and correspond to known $\mathrm{K}$ conductances determined by electrophysiological techniques. Synaptosomes are a convenient mammalian system in which to study modulation of $\mathrm{K}$ channel activity; use of synaptosomes allows a parallel examination of the physiology, pharmacology, and biochemistry of presynaptic $\mathrm{K}$ channels.

Much evidence suggests that protein kinase $\mathrm{C}-$ calcium/phospholipid-dependent protein kinase, "C kinase" (Takai et al., 1979)-plays an important role in neuronal function. Activators of $\mathrm{C}$ kinase can modulate neurotransmitter release in hippocampal slices (Malenka et al., 1987), in cultured embryonic brain neurons (Zurgil et al., 1986), and in synaptosomes prepared from striatum, hippocampus, and other forebrain structures (Lynch and Bliss, 1986; Nichols et al., 1987; Shu and Selmanoff, 1988). Protein kinase $\mathrm{C}$ may be involved in long-term potentiation (LTP), a mammalian model of learning (Akers et al., 1986; Malenka et al., 1986; Hu et al., 1987; Lovinger et al., 1987). The mechanisms that underlie $C$ kinase modulation of neurotransmitter release or its involvement in LTP have not yet been elucidated. Either of these effects could result from modulation of $\mathrm{K}$ channel activity because electrophysiological evidence indicates that activators of $\mathrm{C}$ kinase inhibit $\mathrm{K}$ conductances in hippocampal slices (Baraban et al., 1985), in cultured or acutely dissociated hippocampal neurons (Doerner et al., 1987), and in cultured dorsal root ganglion neurons (Werz and Macdonald, 1987). Furthermorc, $C$ kinase has becn implicated in a simple form of invertebrate learning which results, in part, from modulation of $\mathrm{K}$ conductances (Farley and Auerbach, 1986).

With the aforementioned observations in mind, we investigated the modulation of rat brain synaptosome $K$ channels by $s n$-1,2-dioctanoylglycerol (diC8), an analog of diacylglycerol (DG) that activates protein kinase C. A preliminary report of some of our findings has been published (Colby and Blaustein, 1987).

\section{Materials and Methods \\ Materials}

DG analogs (diC8 and OAG) in chloroform were obtained from Avanti Polar Lipids (Birmingham, AL). Deoxy-diC8 was generously donated by Dr. R. M. Bell, Duke University. Immediately before use, aliquots of these compounds were dried under a stream of nitrogen and resuspended in dimethylsulfoxide (DMSO). Dilutions were made with a buffered salt solution $(5 \mathrm{~K})$ described below. Final DMSO concentration did not exceed $0.1 \%$ and had no effect on ${ }^{86} \mathrm{Rb}$ efflux (not shown). DG analogs were sonicated before use. Sphingosine-SO ${ }_{4}$ (Sigma Chemical Co., St. Louis) was dissolved in ethanol and diluted with $5 \mathrm{~K}$ buffer. Final ethanol concentration did not exceed $0.1 \%$, a concentration that had no effect on ${ }^{86} \mathrm{Rb}$ efflux (not shown). 1-(5-Isoquinolinesulfonyl)-2- 


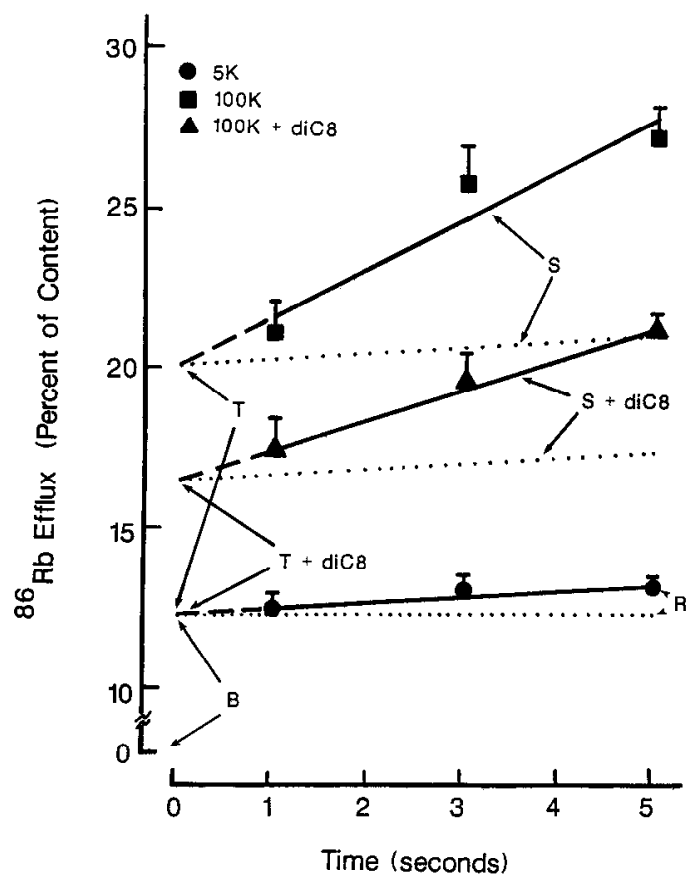

Figure 1. Effect of diC8 on time course of ${ }^{86} \mathrm{Rb}$ efflux from hippocampal synaptosomes. A representative time course is shown; components of $\mathrm{Rb}$ efflux illustrated here $(\mathrm{R}, \mathrm{B}, \mathrm{S}, \mathrm{T})$ are fully described in Materials and Methods. Each point represents the mean of 3-5 individual determinations \pm SE. Similar results were observed in 2 additional experiments. The solid lines were determined by linear-regression analysis. The bottum dotted line is parallel to the abscissa; the 2 upper dotted lines are parallel to the $5 \mathrm{~K}$ line and illustrate the increase in slope caused by depolarizing efflux solution. $\Delta \mathrm{K}$, the $\mathrm{K}$-stimulated ${ }^{86} \mathrm{Rb}$ efflux, includes 2 distinguishable $\mathrm{Rb}$ efflux components, $\mathrm{T}$ (ordinate-intercept) and $S_{v}$ (part of the increase in slope, "S"), that correspond to 2 different voltage-gated $\mathrm{K}$ channels (see Materials and Methods and Bartschat and Blaustein, 1985a). Incubation of hippocampal synaptosomes with 150 $\mu \mathrm{M}$ diC8 for $6 \mathrm{~min}$ inhibited both $\mathrm{T}$ and $\mathrm{S}$, suggesting that the activity of both types of voltage-gated $\mathrm{K}$ channels can be modulated by $\mathrm{C}$ kinase. DiC8 had no effect on efflux in $5 \mathrm{~K}$ (not shown).

methylpiperazine (H-7) was purchased from Seikagaku America, Inc. (St. Petersburg, FL). Crude venom from the scorpion Centruroides sculpturatus was purchased from Sigma; dendrotoxin (" $\alpha$-DaTX"; see Harvey and Karlsson, 1980) was purified from crude Dendroaspis angusticeps venom (Sigma) as described (Blaustein et al., 1988). ${ }^{86} \mathrm{RbCl}$ was obtained from New England Nuclear (Boston). All other reagents were obtained from commercial sources in the highest grade available.

\section{Methods}

Preparation of synaptosomes. Hippocampal or striatal $\mathbf{P}_{2}$ synaptosomes were prepared from female Sprague-Dawley rats, 100-125 gm, as described (Krueger et al., 1979). The loosely packed portion of the pellet from the second high-speed $(10,000 \times g)$ centrifugation $\left(\mathrm{P}_{2}\right.$ pellet $)$, enriched with nerve terminals, was resuspended in $0.32 \mathrm{M}$ sucrose and saved; the dense (bottom) part of the pellet (containing primarily mitochondria) was discarded. $\mathrm{K}$ channel function in $\mathrm{P}_{2}$ synaptosomes is identical to that seen in synaptosomes that have been purified on a 1 -step sucrose density gradient (K. A. Colby and M. P. Blaustein, unpublished observations). The synaptosomes were slowly equilibrated with a physiological salt solution ( $5 \mathrm{~K}$ ), containing (in $\mathrm{mM}$ ) $\mathrm{NaCl}, 145$; $\mathrm{KCl}, 5 ; \mathrm{RbCl}, 0.1 ; \mathrm{MgCl}_{2}, 2$; glucose, $10 ; \mathrm{NaH}_{2} \mathrm{PO}_{4}, 0.5$; and HEPES, 10 , adjusted to $\mathrm{pH} 7.4$. After equilibration the synaptosomes were centrifuged, and the resulting pellet was resuspended in a small volume of $5 \mathrm{~K}$ buffer (composition as above) containing $100 \mu \mathrm{M} \mathrm{Ca}$. The final protein concentration of the resuspended synaptosomes was $3-4 \mathrm{mg} /$ $\mathrm{ml}$.

Synaptosome ${ }^{86} \mathrm{Rb}$ efflux assay. Efflux of ${ }^{86} \mathrm{Rb}$ from the synaptosomes was measured as previously described (Bartschat and Blaustein, 1985a, b). Briefly, the resuspended synaptosomes were loaded with tracer (to a steady-state ${ }^{86} \mathrm{Rb}$ level) by incubation with $10-20 \mu \mathrm{Ci}{ }^{86} \mathrm{Rb} / \mathrm{ml}$ syn- aptosomes (3-4 mg protein $/ \mathrm{ml}$ ) for $30 \mathrm{~min}$ at $30^{\circ} \mathrm{C}$. Aliquots of the ${ }^{86} \mathrm{Rb}$-loaded synaptosomes were added, at timed intervals, to tubes containing diC8 (or other DG analogs) or an appropriate vehicle; these suspensions were preincubated at $37^{\circ} \mathrm{C}$ for a fixed amount of time, usually 6-9 min (see Results). When sphingosine was used, it was included along with diC8 during this preincubation. In the experiments with $\mathrm{H}-7$, the synaptosomes were first preincubated for $9 \mathrm{~min}$ with or without $\mathrm{H}-7$, before incubation with $\mathrm{diC} 8$.

After the preincubation period, an aliquot of each sample was transferred to a glass fiber filter (Schleicher and Schuell \#25). The synaptosomes trapped on the filter were rinsed with $5 \mathrm{~K}$ buffer (containing $0.1 \%$ BSA) and subjected to gentle vacuum filtration to remove extrasynaptosomal ${ }^{86} \mathrm{Rb}$. $\mathrm{Rb}$ efflux was stimulated by addition of an efflux solution at a constant time (no later than $10 \mathrm{sec}$ ) after the final $5 \mathrm{~K}$ wash. Efflux solutions contained either $5 \mathrm{~mm} \mathrm{KCl}$ (control) or $50-100 \mathrm{~mm} \mathrm{KCl}$ (to depolarize the synaptosomes) with or without $1 \mathrm{mM} \mathrm{CaCl}_{2}$. The composition of the depolarizing solutions $(50$ or $100 \mathrm{~K})$ was similar to that of the $5 \mathrm{~K}$ solution, except that $\mathrm{KCl}$ replaced $\mathrm{NaCl}$ mole-for-mole; when $1 \mathrm{mM} \mathrm{CaCl}{ }_{2}$ was added $(50 \mathrm{~K} / \mathrm{Ca}$ or $100 \mathrm{~K} / \mathrm{Ca})$, the concentration of $\mathrm{MgCl}_{2}$ was decreased to $1 \mathrm{mM}$. Efflux was measured for $1-5 \mathrm{sec}$ (timed with a metronome) and was terminated by addition of an isotonic buffered stop solution containing (in $\mathrm{mM}$ ) tetraethylammonium chloride, 145; tetrabutylammonium chloride, $5 ; \mathrm{RbCl}, 0.1 ; \mathrm{NiCl}_{2}, 10 ; \mathrm{MgCl}_{2}, 10$ and HEPES, 10, titrated to $\mathrm{pH} 7.4$ with $\mathrm{NaOH}$. Vacuum filtration was used to collect the efflux and stop solutions. The radioactivity in the filtrate (representing ${ }^{86} \mathrm{Rb}$ efflux) and that on the filter (containing the immobilized synaptosomes) were quantified by liquid scintillation spectrometry. The percentage of total radioactivity released during the efflux period was calculated using the following formula:

$$
{ }^{86} \mathrm{Rb} \text { efflux }(\% \text { of total })=\frac{(\mathrm{cpm} \text { in filtrate })}{(\mathrm{cpm} \text { in filtrate })+(\mathrm{cpm} \text { in filter })} \times 100
$$

Components of ${ }^{86} \mathrm{R} b$ efflux. Hippocampal synaptosomes (Fig. 1), like those prepared from rat forebrain (Bartschat and Blaustein, 1985a, b) and from rat corpus striatum (not shown), exhibit several kinetically and pharmacologically distinct components of $\mathrm{Rb}$ efflux: a resting efflux ("R"), a K-stimulated, voltage-gated component (" $\Delta \mathrm{K}$ "), and a $\mathrm{Ca}$ dependent component (" $\Delta \mathrm{Ca}$ "). The ${ }^{86} \mathrm{Rb}$ efflux into $5 \mathrm{~K}$ (nondepolarizing) solution includes a small, time-dependent "resting efflux" ("R," $0.3-0.5 \% / \mathrm{sec}$ ) and a larger, time-independent "background" ("B," 8$12 \%$ of the "zero-time" Rb efflux; Bartschat and Blaustein, 1985a; see also Fig. 1). The "background" includes tracer that was incompletely removed during the preceding washes.

The K-stimulated efflux $(\Delta \mathrm{K})$ is the efflux into $50 \mathrm{~K}$ or $100 \mathrm{~K}$ minus the efflux into $5 \mathrm{~K} ; \Delta \mathrm{K}$ can be divided into 2 components, component " $T$ " and component " $S$," on the basis of time-course experiments in which ${ }^{86} \mathrm{Rb}$ efflux is measured for intervals of $1-5 \mathrm{sec}$ (see Fig. 1). Component $\mathrm{T}$ is the increment in the ordinate-intercept of the extrapolated time-course line caused by depolarization. This component represents efflux through a rapidly inactivating (within $1 \mathrm{sec}$ ), voltage-gated $\mathrm{K}$ channel that is blocked by relatively low concentrations of 4-aminopyridine $\left(\mathrm{IC}_{50} \simeq 0.2 \mathrm{~mm}\right.$; Bartschat and Blaustein, 1985a) and by $\alpha$-DaTX (Benishin et al., 1988; Blaustein et al., 1988), and thus probably corresponds to the "A current" (Rogawski, 1985).

Component $S$ is the increase in the slope of the line through the various time points measuring $R b$ efflux when $5 K$ is replaced by depolarizing solutions (see Fig. 1); $S$ can be further divided into 2 components: " $S_{R}$ " and " $S_{\mathrm{v}}$." Component $S_{\mathrm{R}}$ represents efflux through the ohmic "resting $\mathrm{K}$ channels" that results from the increase in electrical driving force during depolarization (Bartschat and Blaustein, 1985a). At the $\mathrm{K}$ concentrations used in our experiments, approximately one-half to twothirds of component $S$ is attributable to component $S_{R}$. The remaining one-third to one-half (component $S_{v}$ ) cannot be accounted for by electrodiffusion and appears to represent efflux through a voltage-gated, noninactivating $\mathrm{K}$ channel that may correspond to the "delayed rectifier" (Hille, 1984). Component $S_{\mathrm{v}}$ is sensitive to low concentrations of phencyclidine $\left(\mathrm{IC}_{50} \simeq 1-2 \mu \mathrm{M}\right.$; Bartschat and Blaustein, 1986); it is also selectively blocked by crude venoms from various scorpions (Schneider et al., 1988) and by cetain newly identified polypeptide toxins from the snake, D. angusticeps (Benishin et al., 1988).

The Ca-dependent efflux ( $\Delta \mathrm{Ca}$; Fig. 2) equals the efflux into $50 \mathrm{~K} / \mathrm{Ca}$ or $100 \mathrm{~K} / \mathrm{Ca}$ minus the efflux into $50 \mathrm{~K}$ or $100 \mathrm{~K}$, respectively. This corresponds to efflux through $\mathrm{Ca}$-activated, voltage-gated $\mathrm{K}$ channels (Bartschat and Blaustein, 1985b; Blaustein et al., 1988). 
A

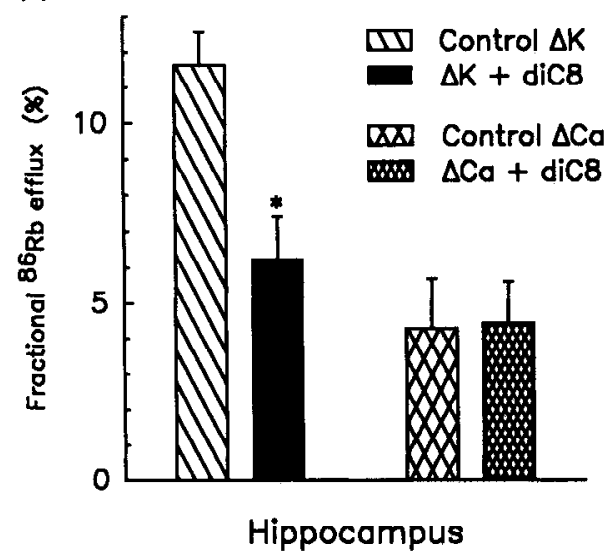

B

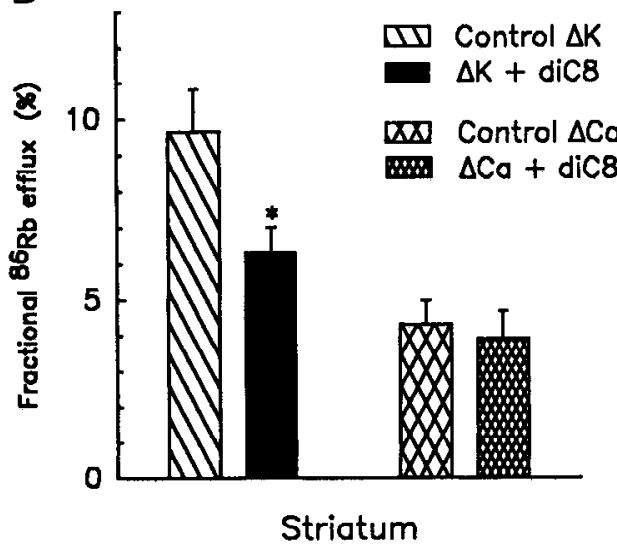

Figure 2. Effect of diC8 on ${ }^{86} \mathrm{Rb}$ efflux from hippocampal or striatal synaptosomes. $\Delta \mathrm{K}$ (K-stimulated $\mathrm{Rb}$ efflux) $=(\mathrm{efflux}$ into $50 \mathrm{~K}$ or $100 \mathrm{~K})-$ (emux into $5 \mathrm{~K}$ ), $\Delta \mathrm{Ca}$ (Ca-dependent, $\mathrm{K}$-stimulated $\mathrm{Rb}$ emux) $=$ (emlux into $50 \mathrm{~K} / \mathrm{Ca}$ or $100 \mathrm{~K} / \mathrm{Ca})-(\mathrm{emlux}$ into $50 \mathrm{~K}$ or $100 \mathrm{~K}$ ). $A$, Hippocampal synaptosomes were incubated with $150 \mu \mathrm{M} \mathrm{diC} 8$ for $6 \mathrm{~min}$ at $37^{\circ} \mathrm{C}$ before ${ }^{86} \mathrm{Rb}$ efflux was measured for 5 sec. DiC 8 markedly reduced $\Delta \mathrm{K}$ but had no effect on $\Delta \mathrm{Ca}$. Results from one experiment are shown (values are means of 4 individual determinations \pm SE). Similar results were seen in 2 additional experiments. The mean decrease in $\Delta \mathrm{K}$ with $\mathrm{diC} 8$ in 3 experiments was $44 \%$ (range, $41-46 \%$ inhibition). There was no change in $\Delta \mathrm{Ca}$ by diC8; mean $\Delta \mathrm{Ca}+\mathrm{diC} 8=101 \%$ control $\Delta \mathrm{Ca}$ (range, $83-118 \%$ control). ${ }^{*}$, significantly different from control $\Delta \mathrm{K}, p<0.05$. $B$, Striatal synaptosomes were exposed to $150 \mu \mathrm{M} \mathrm{diC8}$ as described above. Results from a representative experiment are illustrated (values are the means of 4-5 individual determinations $\pm \mathrm{SE}$ ). DiC8 exposure decreased $\Delta \mathrm{K}$ (mean inhibition seen in 3 experiments was $25 \%$; range, $19-34 \%$ ) but had no effect on $\Delta \mathrm{Ca}$ (mean $\Delta \mathrm{Ca}+\mathrm{diC} 8=102 \%$ control $\Delta \mathrm{Ca}$; range, $91-112 \%$ control; measured in 2 separate experiments). ${ }^{*}$, significantly different from control $\Delta \mathrm{K}, p<0.05$.

Protein determination. Protein concentration was determined as described by Smith et al. (1985) using BSA as the standard.

Statistical analysis. Significance was determined by a 2-tailed Student's $t$ test. A $p$ value of less than 0.05 was considered to be significant. Where representative experiments are illustrated in the figures, similar results were obtained in at least 2 separate experiments with an $N$ of 4-6 for cach condition during cach expcriment. The standard errors (SE) of the $\Delta \mathrm{K}$ and $\Delta \mathrm{Ca}$ values were calculated as follows (see Nachshen and Blaustein, 1979):

$$
\begin{aligned}
\mathrm{SE}(\Delta \mathrm{K}) & =\bigvee\left\{[\mathrm{SE}(5 \mathrm{~K})]^{2}+[\mathrm{SE}(50 \mathrm{~K})]^{2}\right\} \\
\mathrm{SE}(\Delta \mathrm{Ca}) & \left.=\bigvee\{\mathrm{SE}(50 \mathrm{~K})]^{2}+[\mathrm{SE}(50 \mathrm{~K}+\mathrm{Ca})]^{2}\right\}
\end{aligned}
$$

\section{Results}

\section{Effects of diC8 on $K$-stimulated $R b$ efflux $(\Delta K)$ and Ca-dependent $R b$ efflux ( $\triangle C a$ )}

Figure $2 A$ shows data from a representative experiment in which the effect of diC8 was tested on $\mathrm{Rb}$ efflux from hippocampal synaptosomes. Exposure to diC8 significantly inhibited $\Delta \mathrm{K}$, but did not affect $\Delta \mathrm{Ca}$. Although not illustrated here, diC8 had no significant effect on the resting efflux component. Virtually identical results were obtained with striatal synaptosomes (Fig. 2B), except that the inhibition of $\Delta \mathrm{K}$ was somewhat smaller in magnitude. In subsequent experiments we focused exclusively on the effects of diC8 on hippocampal synaptosomes.

\section{DiC'8 treatment inhibits 2 types of voltage-gated K channels}

The K-stimulated $\mathrm{Rb}$ efflux is due to efflux through 2 voltagegated $K$ channels (corresponding to components $T$ and $S_{v}$ ), as well as to an increase in electrodiffusion through resting $\mathrm{K}$ channcls (component $\mathrm{S}_{\mathrm{R}}$; scc Mcthods and Blaustcin et al., 1988).

Time-course experiments demonstrated that diC8 inhibited both voltage-gated components of $\Delta K$ (Fig. 1): the ordinateintercept (component $T$ ) and the slope (part of which is component $S_{\mathrm{V}}$ ) of the $100 \mathrm{~K}+$ diC8 line were both decreased with respect to the control $100 \mathrm{~K}$ line. This observation suggests that the activity of both the noninactivating $K$ channel and the inactivating $\mathrm{K}$ channel can be modulated by $\mathrm{C}$ kinase.

Pharmacological evidence supports this hypothesis (Fig. $3 A$ ): diC8 still decreased ${ }^{86} \mathrm{Rb}$ efflux in the presence of $\alpha$-DaTX, a polypeptide from $D$. angusticeps venom that specifically blocks component T (Benishin et al., 1988; Blaustein et al., 1988). Furthermore, diC 8 inhibition was still apparent in the presence of crude venom from the scorpion $C$. sculpturatus that specifically blocks component $S_{v}$ (Blaustein et al., 1988; Schneider et al., 1988) through activity that appears identical to that of noxiustoxin (Carbone et al., 1987). However, when components T and $S_{\mathrm{V}}$ were both completely inhibited by a high concentration (10 mM) of 4-aminopyridine (4-AP; Bartschat and Blaustein, 1985a), diC8 had no further effect on the residual $\Delta K$, component $S_{R}$ (see Materials and Methods).

It is possible to determine the relative contributions of the various components of $\mathrm{Rb}$ efflux using inhibitors, such as $C$. sculpturatus venom and $\alpha$-DaTX, that selectively block, respectively, components $S_{\mathrm{V}}$ (Schneider et al., 1988) and T (Benishin et al., 1988; Blaustein et al., 1988). Component $S_{R}$, the toxin- and 4-AP-insensitive increase in efflux due to electrodiffusion in depolarizing solutions, constitutes a significant portion (usually 50-60\%) of $\Delta \mathrm{K}$ (right-hand bar in Fig. $3 B$ ). If one subtracts component $S_{\mathrm{R}}$ from the total $\Delta \mathrm{K}$, the remaining fraction of $\Delta \mathrm{K}$ represents the efflux through the 2 classes of voltagegated $\mathrm{K}$ channels. In the experiment illustrated in Figure 3, the total $\Delta \mathrm{K}$ was 12.9 units, 6.3 units of which was contributed by component $S_{R}$. The fraction of $\Delta K$ corresponding to efflux through voltage-gated channels (i.e., components $S_{v}+T$ in Fig. $3 B$ ) was therefore 6.6 units. Addition of diC8 reduced this fraction of $\Delta \mathrm{K}$ to 2.2 units (total $\Delta \mathrm{K}+$ diC8 equals 8.5 units minus 6.3 units from component $S_{R}$ ), representing a $70 \%$ inhibition of ${ }^{86} \mathrm{Rb}$ efflux through the voltage-gated $\mathrm{K}$ channels (black bar in Fig. 3A). Analysis of this sort revealed that $150 \mu \mathrm{M}$ diC8 rou- 

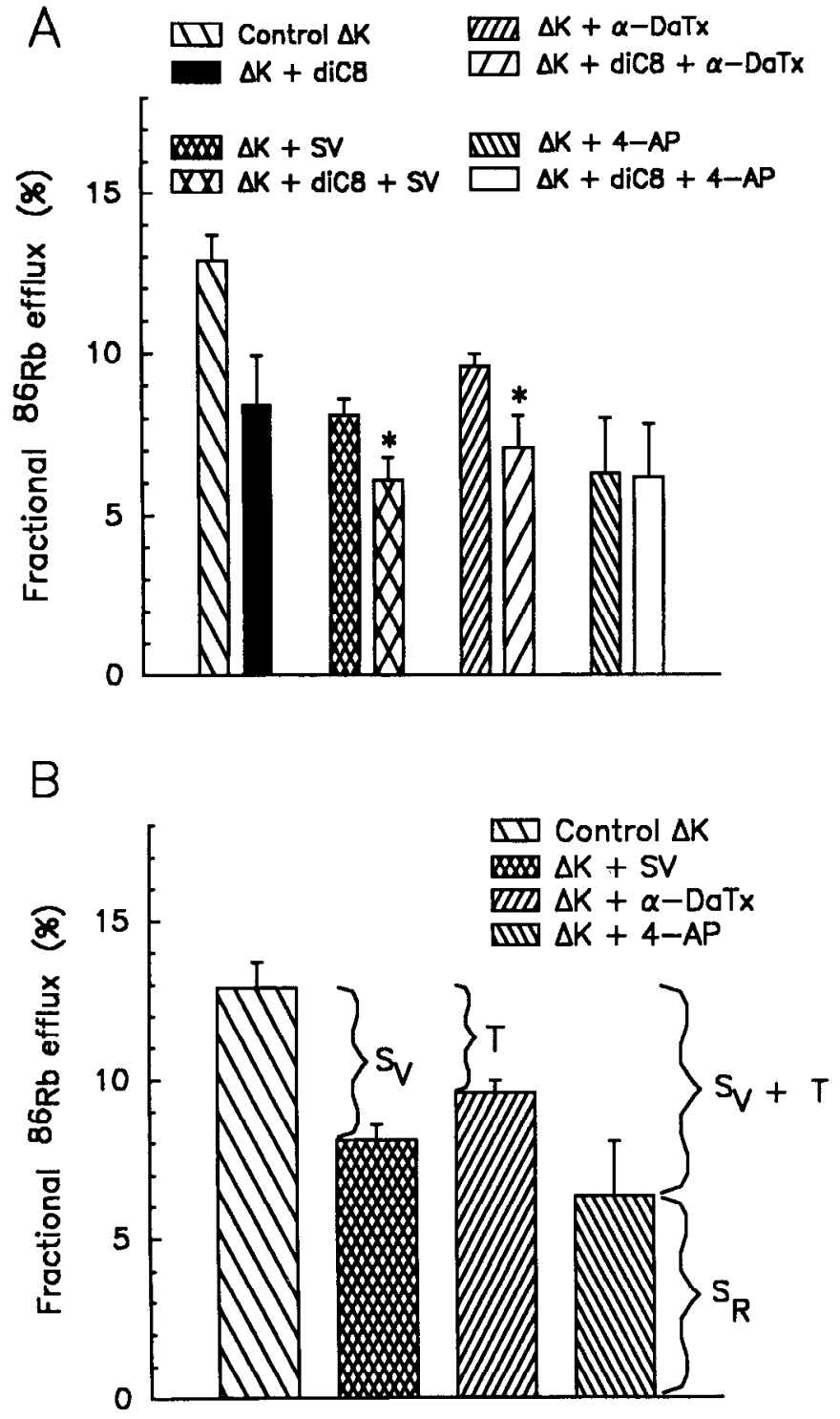

Figure 3. Effect of $\mathrm{K}$ channel blockers on diC8 inhibition of $\Delta \mathrm{K} . A$, Hippocampal synaptosomes were incubated for $9 \mathrm{~min}$ with $150 \mu \mathrm{M}$ $\mathrm{diC} 8 \pm 5 \mu \mathrm{g} / \mathrm{ml}$ crude scorpion (C. sculpturatus) venom (SV) to block component $S_{\mathrm{v}}, 100 \mathrm{nM} \alpha$-DaTX to block component T, or $10 \mathrm{~mm} 4$-AP to block both components $\mathrm{T}$ and $\mathrm{S}_{\mathrm{v}}$. DiC8 further inhibited ${ }^{86} \mathrm{Rb}$ efflux in the presence of either SV or $\alpha$-DaTX, supporting the conclusion from the time-course experiment (Fig. 1) that both a rapidly inactivating, voltage-gated $\mathrm{K}$ channel and a noninactivating, voltage-gated $\mathrm{K}$ channel were inhibiled by diC8. DiC8 had no further effect when components $\mathrm{T}$ and $\mathrm{S}_{\mathrm{v}}$ were completely blocked with 4 -AP. A representative experiment is shown; data are expressed as means of 4-6 individual measurements $\pm \mathrm{SE}$. All values are significantly different from control $\Delta \mathrm{K}$, $p<0.05$. $^{*}$, significantly different from SV or $\alpha$-DaTX alone, $p<0.05$. $B$, The relative contributions of components $\mathrm{T}\left(\alpha\right.$-DaTX-sensitive), $\mathrm{S}_{\mathrm{v}}$ (scorpion venom-sensitive), and $\mathrm{S}_{\mathrm{R}}(\alpha$-DaTX-, SV-, and 4-AP-insensitive) to the total $\Delta \mathrm{K}$ value are shown. The $\alpha$-DaTX-, SV-, and 4-APinsensitive portion of $\Delta K\left(S_{R}=50-60 \%\right.$ of total $\left.\Delta K\right)$ is the increased efflux through resting $\mathrm{K}$ channels as a result of depolarization (see $\mathrm{Ma}$ terials and Methods). DiC8 therefore blocked a major portion (70\%) of the part of $\Delta \mathrm{K}$ that represents efflux through voltage-gated $\mathrm{K}$ channels (components $\mathrm{S}_{\mathrm{v}}$ and $\mathrm{T}$ ).

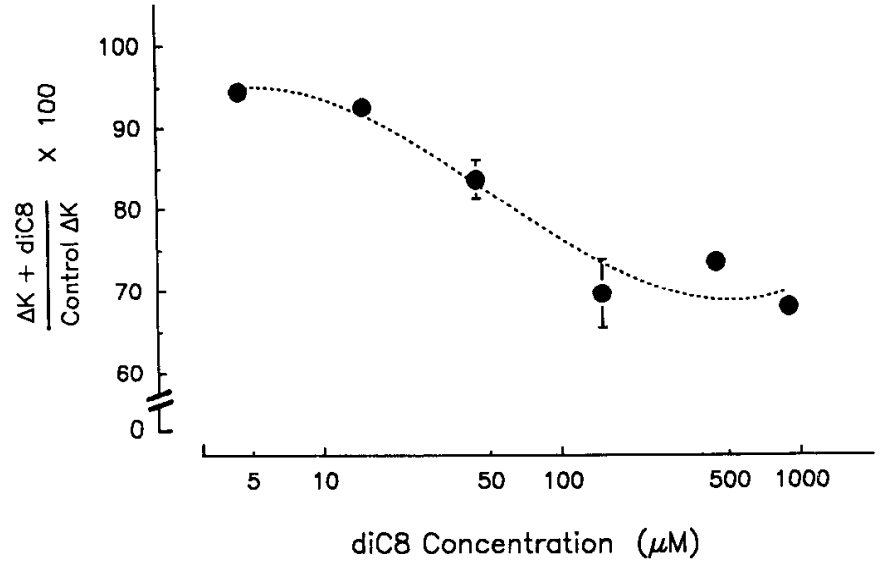

Figure 4. Concentration dependence of diC8 inhibition of $\Delta \mathrm{K}$. Hippocampal synaptosomes were incubated for $7 \mathrm{~min}$ at $37^{\circ} \mathrm{C}$ with concentrations of diC 8 from 4.5 to $900 \mu \mathrm{M}$. ${ }^{86} \mathrm{Rb}$ efflux was then measured for $5 \mathrm{sec}$. Inhibition of $\Delta \mathrm{K}$ could be seen at concentrations as low as 15 $\mu \mathrm{M} ; 50 \mu \mathrm{M}$ diC 8 produced half-maximal inhibition (an approximatcly $20-25 \%$ reduction in total $\Delta \mathrm{K}$ ); there was little additional inhibition at concentrations greater than $150 \mu \mathrm{M}$. The data points represent the mean inhibition seen in 2-3 separate experiments, except for the $150 \mu \mathrm{M}$ point (measured in 6 experiments) and the $900 \mu \mathrm{M}$ point (measured in only 1 experiment); $N$ for each experiment was 4-6. Error bars represent the SE of the mean inhibition and are shown only where the SE exceeds the size of the symbol. The dashed line is a computer-fitted curve of the data points.

tinely blocked $60-100 \%$ of the non- $S_{R}$ components of $\Delta K$ that represent efflux through the 2 types of voltage-gated (inactivating and noninactivating) $\mathrm{K}$ channels.

\section{Concentration and time dependence of the diC8 effect}

The magnitude of inhibition of K-stimulated $\mathrm{Rb}$ efflux by diC 8 depended upon both the concentration of diC8 (Fig. 4) and the length of the preincubation (Fig. 5). The maximal inhibition observed in any experiment was approximately a $45-50 \%$ reduction in total $\Delta \mathrm{K}$; inhibition of this magnitude was produced by high concentrations of, or long incubations with, diC8. DiC8, $50 \mu \mathrm{M}$, inhibited the 4-AP-sensitive fraction of $\Delta \mathrm{K}$ (corresponding to components $\mathrm{S}_{\mathrm{v}}$ and $\mathrm{T}$ ) by about $50 \%$; the inhibition plateaued above $150 \mu \mathrm{M} \mathrm{diC} 8$. A similar dose-response relationship with $\mathrm{diC} 8$ has been observed in other systems (Conn et al., 1985).

There were day-to-day variations in the absolute amount of inhibition produced by $150 \mu \mathrm{M} \mathrm{diC} 8$, the concentration used for most of our experiments. In 12 separate experiments in which hippocampal synaptosomes were preincubated with 150 $\mu \mathrm{M} \mathrm{diC} 8$ for $6 \mathrm{~min}$, inhibition ranged from 21 to $47 \%$ of total control $\Delta \mathrm{K}$; the average inhibition was $36 \%$.

Inhibition of $\Delta \mathrm{K}$ by diC 8 was observed only when the synaptosomes were preincubated with the lipid for at least $15 \mathrm{sec}$ before efflux was initiated (Fig. 5). The inhibitory effect was not observed when diC8 was present only in the efflux solution (no preincubation), suggesting that $\mathrm{diC} 8$ was not acting as a direct blocker of synaptosomal K channels (see Discussion). Inhibition of $\Delta \mathrm{K}$ increased with increasing length of preincubation with diC8; half-maximal inhibition was observed after 15-30 sec with $150 \mu \mathrm{M} \mathrm{diC} 8$. The inhibition plateaued after approximately 2 min of preincubation. The effect of diC8 was partially reversed by centrifuging the diC8-treated synaptosomes and resuspending them in lipid-free media for $\mathbf{2 0 ~ m i n ~ b e f o r e ~ e f f l u x ~ w a s ~ m e a - ~}$ sured (not shown). 


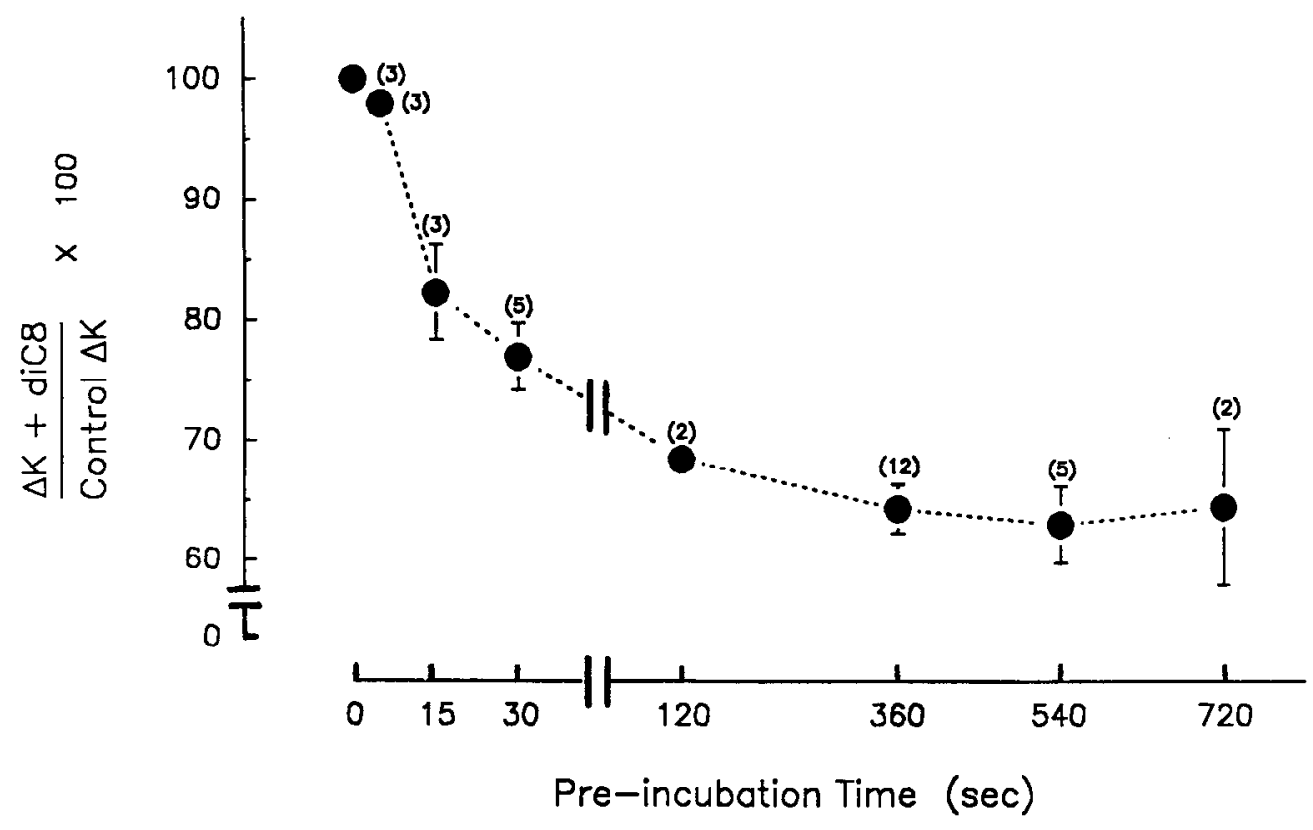

Figure 5. Time dependence of diC8 inhibition of $\Delta \mathrm{K}$. Hippocampal synaptosomes were preincubated with 150 $\mu \mathrm{M}$ diC 8 for $5 \mathrm{sec}$ to $12 \mathrm{~min}$ before ${ }^{86} \mathrm{Rb}$ efflux was measured for $5 \mathrm{sec}$. Inhibition of $\Delta \mathrm{K}$ was apparent following preincubations of at least $15 \mathrm{sec}$ and increased rapidly as the length of preincubation increased up to approximately $2 \mathrm{~min}$, at which point the inhibition began to plateau. Addition of diC8 to the efflux solution alone (no preincubation) or preincubations of less than $15 \mathrm{sec}$ had no effect on control $\Delta \mathrm{K}$. Points shown are the mean inhibition observed in 2-12 separate experiments (number of experiments for each point shown in parentheses); 4-6 individual determinations were made in each experiment. Bars represent the SE of the mean inhibition and are shown only where the SE exceeds the size of the symbol. Note the change in scale after the $30 \mathrm{sec}$ time point.

\section{Structure-activity relationship supports $C$ kinase involvement}

There is a well-defined relationship between the structure of DG analogs and their ability to activate $\mathrm{C}$ kinase; for example, DG analogs that lack the $3^{\prime} \mathrm{OH}$ group do not stimulate $\mathrm{C}$ kinase (Conn et al., 1985). To determine if the diC8-induced inhibition of $\Delta \mathrm{K}$ was due to activation of protein kinase $\mathrm{C}$, we compared the effect of diC8 with that of 1-oleoyl-2-acetylglycerol (OAG), another C-kinase activating DG analog, and with dcoxy-diC8, which does not activate $C$ kinase. As illustrated in Figure 6, $\mathrm{OAG}$ mimicked the inhibitory effect of $\mathrm{diC} 8$ on $\Delta \mathrm{K}$ but appeared to be less potent; in contrast, deoxy-diC8 had no effect on $\Delta \mathrm{K}$.

Two C kinase-activating phorbol esters (Castagna et al., 1982), TPA (12-O-tetradecanoylphorbol 13-acetate) and PDBu (phorbol 12,13-dibutyrate), in concentrations from $10^{-9}$ to $10^{5} \mathrm{M}$, had no effect on any of the components of $\mathrm{Rb}$ efflux from hippocampal or striatal synaptosomes (not shown). Furthermore, neither PDA (phorbol 12,13-diacetate) nor DPB (12-deoxyphorbol 13-isobutyrate), at a concentration of $100 \mathrm{nM}$, affected the K-stimulated $\mathrm{Rb}$ efflux, $\Delta \mathrm{K}$ (not shown).

\section{Inhibitors of $C$ kinase prevent the diC8 effect}

A further test of the hypothesis that the action of diC8 on the $\mathrm{K}$-stimulated $\mathrm{Rb}$ efflux is due to $\mathrm{C}$ kinase activation is to determine if inhibitors of $\mathrm{C}$ kinase can prevent the effect. We examined 2 inhibitors of $\mathrm{C}$ kinase, sphingosine (Hannun et al., 1986) and H-7 (Kawamoto and Hidaka, 1984), for their effects on the inhibition of $\Delta \mathrm{K}$ caused by diC8. Sphingosine inhibits $\mathrm{C}$ kinase activity by interfering with the formation of an active lipid-enzyme complex. It prevented the diC8-induced inhibition of $\Delta \mathrm{K}$ when it was added to synaptosomes concurrently with diC8 (Fig. 7). H-7 inhibits $\mathrm{C}$ kinase through a direct interaction with the catalytic site of the kinase. When synaptosomes were incubated with $\mathrm{H}-7$ before exposure to $\mathrm{diC} 8$, the inhibition caused by diC 8 was significantly reduced (Fig. 7). Neither sphingosine nor H-7, alone, had any effect on resting or K-stimulated efflux (not shown).

\section{Discussion}

Modulation of ion channel activity is an important cellular regulatory mechanism (Kaczmarek, 1987; Reuter, 1987). K channels play a key role in neuronal excitability, repolarization and neurotransmitter release and thus are obvious targets for regulation. Evidence currently available demonstrates that the activity of $K$ channcls in a varicty of systcms can be influcnecd by neurotransmitters, second messengers, and protein kinase activators (Siegelbaum and Tsien, 1983; Levitan, 1985). K channel modulation may underlie fundamental, but poorly understood, processes such as learning and memory (Kandel and Schwartz, 1982; Alkon, 1984). There is thus a great incentive to uncover the mechanisms responsible for the regulation of $\mathrm{K}$ channel activity.

\section{DiC8 blocks ${ }^{86} \mathrm{Rb}$ efflux components corresponding to " $A$ "' and "delayed rectifier" channels}

The data described in this report indicate that certain activators of protein kinase $\mathrm{C}$ modulate the activity of voltage-gated $\mathrm{K}$ channels in synaptosomes from mammalian brain. Incubation of hippocampal synaptosomes with $\mathrm{diC} 8$ markedly inhibited $\mathrm{K}$-stimulated $\mathrm{Rb}$ efflux corresponding to 2 types of $\mathrm{K}$ channels a rapidly inactivating, voltage-gated $\mathrm{K}$ channel and a noninactivating, voltage-gated $\mathrm{K}$ channel. The effect was both time and concentration dependent. Experiments with $\alpha$-DaTX, which blocks $\mathrm{T}$, and $C$. sculpturatus venom, which blocks $\mathrm{S}_{\mathrm{v}}$, demonstrated that diC8 blocked both inactivating and noninactivating $\mathrm{K}$ channels; diC8 had no further effect when components $\mathrm{T}$ and $\mathrm{S}_{\mathrm{v}}$ were both completely blocked by $10 \mathrm{~mm}$ 4-AP.

The maximum inhibition of $\Delta \mathrm{K}$ observed in our experiments was approximately $50 \%$ of the total control $\Delta \mathrm{K}$. About half of the $\mathrm{K}$-stimulated ${ }^{86} \mathrm{Rb}$ efflux is attributable to electrodiffusion through the "resting" $\mathrm{K}$ conductance (see Materials and Methods, Fig. 3, and Bartschat and Blaustein, 1985a); thus, a 50\% reduction in $\Delta \mathrm{K}$ represents virtually complete shut-down of the voltage-gated $\mathrm{K}$ channels. Furthermore, diC8 specifically inhib- 


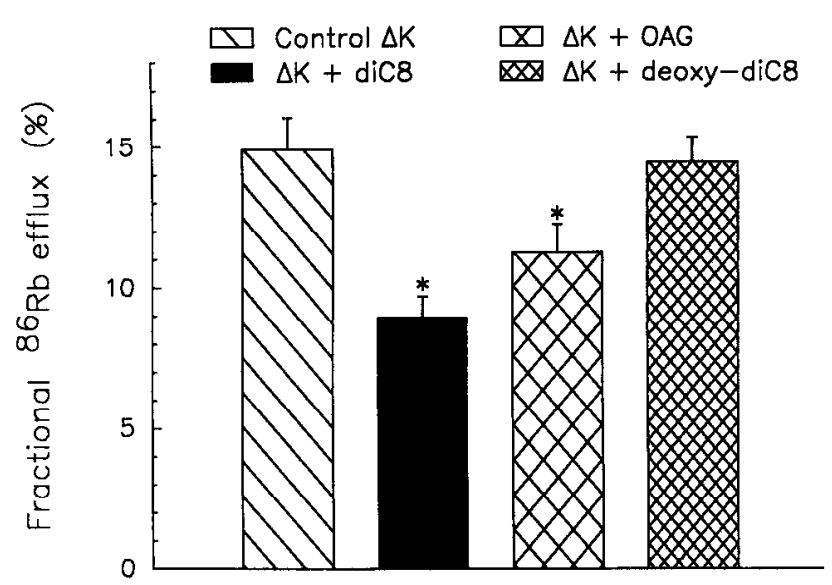

Figure 6. Effect of DG analogs on ${ }^{86} \mathrm{Rb}$ efflux from hippocampal synaptosomes. Hippocampal synaptosomes were incubated with $150 \mu \mathrm{M}$ diC8, deoxy-diC8, or OAG for 7-9 min before ${ }^{86} \mathrm{Rb}$ efflux was measured for $5 \mathrm{sec}$. OAG inhibited $\Delta \mathrm{K}$, but was slightly less effective than diC8; deoxy-diC8 had no effect on $\Delta \mathrm{K}$. Data shown are from 2 representative experiments (one with each analog) and are expressed as the means \pm SE. $N=10-12$ for control $\Delta \mathrm{K}$ and $\Delta \mathrm{K}+\operatorname{diC} 8 ; N=4-6$ for each analog. Similar results were obtained in at least 2 separate experiments. ${ }^{*}$, significantly different from control $\Delta \mathrm{K}, p<0.05$

ited the K-stimulated component of $\mathrm{Rb}$ efflux; it had no effect on $\Delta \mathrm{Ca}$, the efflux through $\mathrm{Ca}$-activated $\mathrm{K}$ channels, or on resting efflux.

\section{DiC8 blocks $K$ channels by activating $C$ kinase}

Pharmacological evidence supports the idea that the diC8 inhibition of the $\Delta K$ results from activation of protein kinase $C$. Structure-activity data showed that inhibition of $\Delta \mathrm{K}$ was only produced by DG analogs capable of activating $C$ kinase; deoxydiC8, an inactive analog, had no effect on $\mathrm{K}$-stimulated $\mathrm{Rb}$ efflux. Our data indicated that $\mathrm{OAG}$ was less potent at inhibiting $\mathrm{K}$-stimulated Rb efflux. OAG may be less effective at traversing membranes; other studies have shown that, although diC8 and $\mathrm{OAG}$ have similar potencies in activating $\mathrm{C}$ kinase in vitro, diC8 is more effective in stimulating luteinizing hormone release from pituitary cells (Conn et al., 1985).

Two inhibitors of $\mathrm{C}$ kinase, sphingosine and $\mathrm{H}-7$, blocked the diC8 effect. Neither of these inhibitors is completely specific for $\mathrm{C}$ kinase; however, they inhibit $\mathrm{C}$ kinase by different mechanisms. The fact that both were able to prevent the diC8 effect strongly suggests that $\mathrm{C}$ kinase is involved in the diC8-induced inhibition of K-stimulated $\mathrm{Rb}$ efflux.

When evaluating the mode of action of any compound that inhibits ion channel activity, one must consider the possibility that the agent in question simply blocks the channel directly. While it is conceivable that diC8 acts externally to block synaptosome $\mathrm{K}$ channels rather than internally through activation of a second-messenger system, the following evidence makes this unlikely. First, diC8 had no effect on ${ }^{86} \mathrm{Rb}$ efflux when it was present only in the efflux solution and had not been preincubated with the synaptosomes. In contrast, compounds that inhibit ${ }^{86} \mathrm{Rb}$ efflux by a direct block of $\mathrm{K}$ channels (e.g., dendrotoxins, 4-AP, phencyclidine, tetraethylammonium) do not require a preincubation period and are effective when present only in the efflux solution (Bartschat and Blaustein, 1985a, b, 1986; Blaustein et al., 1988). Second, deoxy-diC8, a structural analog of diC8 that differs only in the absence of the $3^{\prime} \mathrm{OH}$ group,

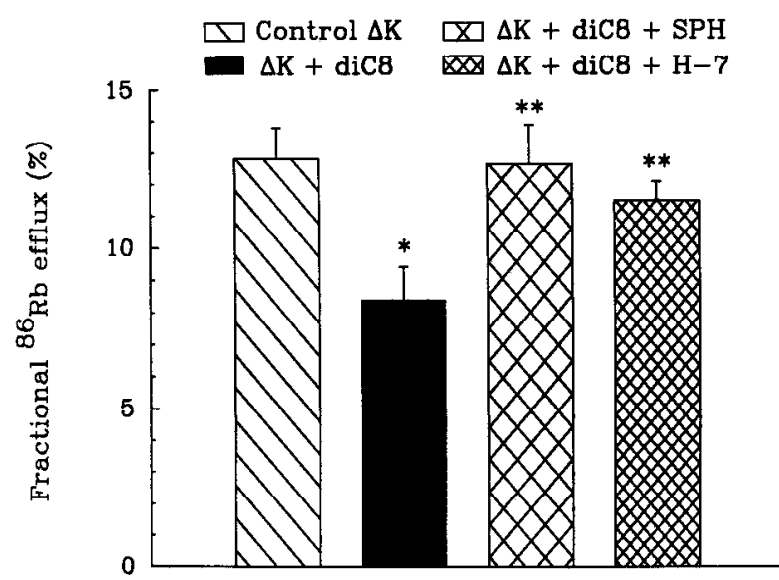

Figure 7. Effect of $\mathrm{C}$ kinase inhibitors on diC8 inhibition of $\Delta \mathrm{K}$. Hippocampal synaptosomes were incubated with $150 \mu \mathrm{M} \mathrm{diC8} \pm 100 \mu \mathrm{M}$ sphingosine ( $S P H$ ) for 9 min or wilh $50 \mu \mathrm{M}$ H-7 for 9 min followed by incubation with diC8 for $9 \mathrm{~min}$, before ${ }^{86} \mathrm{Rb}$ efflux was measured for 5 sec. SPH completely prevented the inhibition of $\Delta \mathrm{K}$ by diC8; H-7 signiticantly reduced the diC 8 -induced inhibition of $\Delta \mathrm{K}$. Neither SPH nor $\mathrm{H}-7$ alone had any effect on $\Delta \mathrm{K}$ (not shown). Data from 2 representative experiments (one with each inhibitor) are illustrated as the means \pm SE. $N=8-10$ for control $\Delta \mathrm{K}$ and $\Delta \mathrm{K}+\mathrm{diC} 8 ; N=4-5$ for each inhibitor. Similar results were obtained in at least 2 separate experiments. *, significantly different from control $\Delta \mathrm{K}, p<0.05 ; * *$, significantly different from $\Delta \mathrm{K}+\operatorname{diC} 8$ (alone), $p<0.05$.

had no effect on ${ }^{86} \mathrm{Rb}$ efflux. If diC8 were simply blocking the $\mathrm{K}$ channels externally, it is likely that a closely related analog would have a similar (or at least a partial) effect. Finally, the fact that inhibitors of $C$ kinase blocked the inhibition of ${ }^{86} \mathrm{Rb}$ efflux by diC8 also suggests that diC8 acts internally; it seems unlikely that the effects of an external channel blocker could be antagonized without affecting the properties of the channel itself. In combination with the pharmacological data discussed above, these observations support our hypothesis that diC8 acts within the synaptosome to inhibit ${ }^{86} \mathrm{Rb}$ efflux.

\section{Presynaptic $K$ channels may be modulated by only certain types of $C$ kinase}

Because diC8 appeared to block synaptosome $\mathrm{K}$ channels via activation of protein kinase $\mathrm{C}$, it was somewhat surprising that phorbol esters, which are known to activate $\mathrm{C}$ kinase in vitro, had no effect on $\Delta \mathrm{K}$. There are several possible explanations for this finding.

DG analogs and phorbol esters are often assumed to have identical effects; however, this is not always the case (e.g., Brockenbrough and Korc, 1987; Kolesnick and Paley, 1987; Ways et al., 1987). In fact, Nishizuka (1986) mentions that differences in the actions of phorbols and DG analogs should not be surprising. An important distinction between phorbol esters and DG, the physiological messenger they imitate, is their duration of action (Nishizuka, 1986). The intracellular concentration of DG increases transiently in response to receptor activation and quickly returns to baseline as the lipid is metabolized. In contrast, phorbol esters are not readily degraded within the cell. This difference may underlie seeming incongruities in the effects of DG analogs and phorbol esters and suggests that DG analogs morc closcly replicate normal physiological responses.

Several groups have isolated $\mathrm{C}$ kinase clones that encode structurally distinct forms of C kinase (Coussens et al., 1986; Knopf et al., 1986). The physiological significance of these iso- 
zymes has not yet been established. These isozymes may have distinct physiochemical properties that could include differing sensitivity to activation by phorbol esters; for example, Robinson and coworkers (1987) have identified an isozyme of C kinase that is not activated by phorbol esters. It is possible that presynaptic K channels are modulated only by certain subclasses (perhaps phorbol-insensitive) of $\mathrm{C}$ kinase. While previous studies have demonstrated modulation of postsynaptic $\mathrm{K}$ conductances by phorbol esters (Baraban et al., 1985; Doerner et al., 1987; Werz and Macdonald, 1987), our results are the first to address their effect on presynaptic $\mathrm{K}$ channels. The difference in the response to phorbol esters suggests that the regulation of presynaptic $\mathrm{K}$ channels may not be identical to that of analogous channels located postsynaptically on the soma. Moreover, the situation is complicated by observations suggesting that the relative density of various $\mathrm{K}$ and $\mathrm{Ca}$ channels, a characteristic that would be expected to vary between the terminal and the soma, may determine the response to phorbol esters (Werz and Macdonald, 1987).

Finally, it is likely that activation of $\mathrm{C}$ kinase within the synaptosome has multiple effects. Indeed, $\mathrm{C}$ kinase activation in vivo may promote neurotransmitter release through a dual mechanism, by increasing both the influx of calcium into the presynaptic terminal (our results and Zurgil et al., 1986) and the sensitivity of the exocytotic process to calcium (Knight and Baker, 1983; Nichols et al., 1987). Conceivably, certain isozymes of $\mathrm{C}$ kinase might differentially modulate $\mathrm{K}$ channel function, and influx of calcium, while others preferentially control the Ca sensitivity of processes distal to $\mathrm{Ca}$ entry. Such redundant regulation of the effects of calcium would allow the neuron to maintain fine control over the essential process of transmitter release.

\section{Implications of $C$ kinase modulation of presynaptic $K$ channels}

Activation of protein kinase C by DG analogs (Lynch and Bliss, 1986) or phorbol esters (Zurgil et al., 1986; Malenka et al., 1987; Nichols et al., 1987) produces an increase in neurotransmitter release in a number of different experimental preparations from the mammalian CNS. Our results suggest that this increase in transmitter release may result from a block of the $K$ channels that are responsible for the repolarization phase of the action potential, in a manner analogous to that previously demonstrated in invertebrates (Kandel and Schwartz, 1982). Inhibition of these channels would slow neuronal repolarization, thereby allowing more calcium to enter the presynaptic terminal and, in turn, promoting increased neurotransmitter release. This scenario is supported by observations that $\mathrm{K}$ channel blockers such as $\alpha$-DaTX ("dendrotoxin"; Harvey and Karlsson, 1980), 4-AP, and tetraethylammonium (Glavinovic, 1987) increase neurotransmitter release. Indeed, inhibition of $\mathrm{K}$ channels underlies the increased neurotransmitter release caused by $\mathrm{C}$ kinase activators in the squid giant synapse (Augustine et al., 1986).

In conclusion, our data directly demonstrate that $\mathrm{C}$ kinase activators can modulate $\mathrm{K}$ channel function in the mammalian presynaptic terminal. These results have interesting implications in light of the participation of $\mathrm{K}$ channel modulation in simple forms of invertebrate learning and memory (e.g., Kandel and Schwartz, 1982; Farley and Auerbach, 1986) and the role of protein kinase C in LTP, a mammalian model of synaptic plasticity (e.g., Malenka et al., 1986). Our data strengthen the hypothesis that modulation of voltage-gated $\mathrm{K}$ channels in the presynaptic terminal may be involved in the $C$ kinase-induced increase in neurotransmitter release that is thought to be at least one component of LTP (Malenka et al., 1986).

Studies are currently underway to determine if the inhibition of K-stimulated $\mathrm{Rb}$ efflux by diC 8 is accompanied by a change in the phosphorylation of synaptic proteins. Of particular interest is whether changes in phosphorylation can be detected in peptides, labelcd by $\mathrm{K}$ channel blockers from $D$. angusticeps venom, that are thought to be components of neuronal $\mathrm{K}$ channels (Sorensen and Blaustein, 1987).

\section{References}

Akers, R. F., D. M. Lovinger, P. A. Colley, D. J. Linden, and A. Routtenberg (1986) Translocation of protein kinase C activity may mediate hippocampal long-term potentiation. Science 231: 587-589.

Alkon, D. L. (1984) Calcium-mediated reduction of ionic currents: A biophysical memory trace. Science 226: 1037-1045.

Augustine, G. J., L. R. Osses, S. R. Barry, and M. P. Charlton (1986) Presynaptic mechanism of kinase $\mathrm{C}$ activators at the squid giant synapse. Soc. Neurosci. Abstr. 12: 821.

Baraban, J. M., S. H. Snyder, and B. E. Alger (1985) Protein kinase $\mathrm{C}$ regulates ionic conductance in hippocampal pyramidal neurons: Electrophysiological effects of phorbol esters. Proc. Natl. Acad. Sci. USA 82: 2538-2542.

Bartschat, D. K., and M. P. Blaustein (1985a) Potassium channels in isolated presynaptic nerve terminals from rat brain. J. Physiol. (Lond.) 361: 419-440.

Bartschat, D. K., and M. P. Blaustein (1985b) Calcium-activated potassium channels in isolated presynaptic nerve terminals from rat brain. J. Physiol. (Lond.) 361: 441-457.

Bartschat, D. K., and M. P. Blaustein (1986) Phencyclidine in low doses selectively blocks a presynaptic voltage-regulated potassium channel in rat brain. Proc. Natl. Acad. Sci. USA 83: 189-192.

Benishen, C. G., R. G. Sorensen, W. E. Brown, B. K. Krueger, and M. P. Blaustein (1988) Four polypeptide components of green mamba venom selectively block certain potassium channels in rat brain synaptosomes. Mol. Pharmacol. 34: 152-159.

Blaustein, M. P., D. K. Bartschat, C. G. Benishin, W. E. Brown, K. A. Colby, B. K. Krueger, M. J. Schneider, and R. G. Sorensen (1988) Potassium channels in rat brain synaptosomes: Pharmacology and toxicology. In Proceedings of a NATO Workshop on the Cellular and Molecular Basis of Neuronal Signalling (Synaptic Transmission), H. Zimmermann, ed., pp. 241-261, Springer-Verlag, Berlin.

Brockenbrough, J. S., and M. Korc (1987) Effects of 1-oleoyl-2-acetyl glycerol are distinct from those of phorbol ester in rat pancreatic acini. Life Sci. 40: 1625-1631.

Carbone, E., G. Prestipino, L. Spadavecchia, F. Franciolini, and L. D. Possani (1987) Blocking of the squid axon $\mathrm{K}^{+}$channel by noxiustoxin: A toxin from the venom of the scorpion Centruroides noxius. Pfluegers Arch. 408: 423-431.

Castagna, M., Y. Takai, K. Kaibuchi, K. Sano, U. Kikkawa, and Y. Nishizuka (1982) Direct activation of calcium-activated, phospholipid-dependent protein kinase by tumor-promoting phorbol esters. J. Biol. Chem. 257: 7847-7851.

Colby, K. A., and M. P. Blaustein (1987) Inhibition of voltage-gated $\mathrm{K}$ channels in synaptosomes by $s n$-1,2-dioctanoylglycerol, an activator of C kinase. Soc. Neurosci. Abstr. 13: 310.

Conn, P. M., B. R. Ganong, J. Ebeling, D. Staley, J. E. Neidel, and R. M. Bell (1985) Diacylglycerols release LH: Structure-activity relations reveal a role for protein kinase C. Biochem. Biophys. Res. Commun. 126: 532-539.

Coussens, L., P. J. Parker, L. Rhee, T. L. Yang-Feng, E. Chen, M. D. Waterfield, U. Francke, and A. Ullrich (1986) Multiple, distinct forms of bovine and human protein kinase $C$ suggest diversity in cellular signaling pathways. Science 233: 859-866.

Doerner, D., T. A. Pitler, and B. E. Alger (1987) Selective effects of phorbol esters on $\mathrm{Ca}$ and $\mathrm{K}$ currents in hippocampal neurons. Soc. Neurosci, Abstr. 13: 1004.

Farley, J., and S. Auerbach (1986) Protein kinase C activation induces conductance changes in Hermissenda photoreceptors like those seen in associative learning. Nature 319: 220-223.

Glavinovic, M. I. (1987) Differences in presynaptic action of 4-ami- 
nopyridine and tetraethylammonium at frog neuromuscular junction. Can. J. Physiol. Pharmacol. 65: 747-752.

Hannun, Y. A., C. R. Loomis, A. H. Merrill, Jr., and R. M. Bell (1986) Sphingosine inhibition of protein kinase $C$ activity and of phorbol dibutyrate binding in vitro and in human platelets. J. Biol. Chem. 261: 12604-12609.

Harvey, A. L., and E. Karlsson (1980) Dendrotoxin from the venom of the green mamba, Dendroaspis angusticeps. A neurotoxin that enhances acetylcholine release at neuromuscular junctions. NaunynSchmeideburg's Arch. Pharmacol. 312: 1-6.

Hille, B. (1984) Ionic Channels of Excitable Membranes, Sinauer, Sunderland, MA.

Hu, G.-Y., O. Hvalby, S. I. Walaas, K. A. Albert, P. Skjeflo, P. Anderson, and P. Greengard (1987) Protein kinase C injection into hippocampal pyramidal cells elicits features of long-term potentiation. Nature 328: $426-429$.

Kaczmarek, L. K. (1987) The role of protein kinase C in the regulation of ion channels and neurotransmitter release. Trends Neurosci. 10. 30-34.

Kandel, E. R., and J. H. Schwartz (1982) Molecular biology of learning: Modulation of transmitter release. Science 218: 433-443.

Kawamoto, S., and H. Hidaka (1984) 1-(5-isoquinolinesulfonyl)-2methylpiperazine (H-7) is a selective inhibitor of protein kinase $\mathrm{C}$ in rabbit platelets. Biochem. Biophys. Res. Commun. 125: 258-264.

Knight, D. E., and P. F. Baker (1983) The phorbol ester TPA increases affinity for exocytosis in "leaky" adrenal medullary cells. FEBS Lett. 160: $98-100$

Knopf, J. L., M. H. Lee, L. A. Sultzman, R. W. Kriz, C. R. Loomis, R M. Hewick, and R. M. Bell (1986) Cloning and expression of multiple protein kinase C cDNAs. Cell 46: 491-502.

Kolesnick, R. N., and A. E. Paley (1987) 1,2-Diacylglycerols and phorbol esters stimulate phosphatidylcholine metabolism in $\mathrm{GH}_{3} \mathrm{pi}-$ tuitary cells. J. Biol. Chem. 262: 9204-9210.

Krueger, B. K., R. W. Ratzlaff, G. R. Strichartz, and M. P. Blaustein (1979) Saxitoxin binding to synaptosomes, membranes and solubilized binding sites from rat brain. J. Membr. Biol. 50: 287-310.

Levitan, I. B. (1985) Phosphorylation of ion channels. J. Membr. Biol. 87: 177-190.

Lovinger, D. M., K. L. Wong, K. Murakami, and A. Routtenberg (1987) Protein kinase $\mathrm{C}$ inhibitors eliminate hippocampal long-term potentiation. Brain Res. 436: 177-183.

Lynch, M. A., and T. V. P. Bliss (1986) Long-term potentiation of synaptic transmission in the hippocampus of the rat: Effect of calmodulin and oleoyl-acetyl-glycerol on the release of $\left[{ }^{3} \mathrm{H}\right]$ glutamate. Neurosci. Lett. 5: 171-176.

Malenka, R. C., D. V. Madison, and R. A. Nicoll (1986) Potentiation of synaptic transmission in the hippocampus by phorbol esters. Nature 321: 175-177.

Malenka, R. C., G. S. Ayoub, and R. A. Nicoll (1987) Phorbol esters enhance transmitter release in rat hippocampal slices. Brain Res. 403: 198-203.

Nachshen, D. A., and M. P. Blaustcin (1979) The effects of some organic "calcium antagonists" on calcium influx in presynaptic nerve terminals. Mol. Pharmacol. 16: 579-586.

Nichols, R. A., J. W. Haycock, J. K. T. Wang, and P. Greengard (1987) Phorbol ester enhancement of neurotransmitter release from rat brain synaptosomes. J. Neurochem. 48: 615-621.

Nishizuka, Y. (1986) Studies and perspectives of protein kinase C. Science 233: 305-312.

Reuter, H. (1987) Modulation of ion channels by phosphorylation and second messengers. News Physiol. Sci. 2: 168-171.

Robinson, P. J., C. K. Black, and W. Lovenberg (1987) A subtype of neuronal protein kinase $C$ activity with unique substrate specificity. Soc. Neurosci. Abstr. 13: 309.

Rogawski, M. A. (1985) The A-current: How ubiquitous a feature of excitable cells is it? Trends Neurosci. 8: 214-219.

Schneider, M. J., B. K. Krueger, and M. P. Blaustein (1988) Block of mammalian brain $\mathrm{K}$ channels by three scorpion venoms. Biophys. J. 53: 459a.

Shu, C., and M. Selmanoff (1988) Phorbol esters potentiate rapid dopamine release from median eminence and striatal synaptosomes. Endocrinology 122: 2699-2709.

Siegelbaum, S. A., and R. W. Tsien (1983) Modulation of gated ion channels as a mode of transmitter action. Trends Neurosci. 6: 307313.

Smith, P. C., R. I. Krohn, G. T. Hermanson, A. K. Mallia, F. H. Gartner, M. D. Provenzo, E. K. Fujimoto, N. M. Goeke, B. J. Olson, and D. C. Klink (1985) Measurement of protein using bicinchoninic acid. Anal. Biochem. 150: 76-85.

Sorcnsen, R. G., and M. P. Blaustein (1987) Four polypeptides purified from green mamba venom, which block $\mathrm{K}$ channels, label specific receptors on rat brain synaptic membranes. Soc. Neurosci. Abstr. 13: 530.

Takai, Y., A. Kishimoto, Y. Iwasa, Y. Kawahara, T. Mori, and Y. Nishizuka (1979) Calcium-dependent activation of a multifunctional protein kinase by membrane phospholipids. J. Biol. Chem. 254: 3692-3695

Ways, D. K., R. C. Dodd, and H. S. Earp (1987) Dissimilar effects of phorbol ester and diacylglycerol derivative on protein kinase activity in the monoblastoid U937 cell. Cancer Res. 47: 3344-3350.

Werz, M. A., and R. L. Macdonald (1987) Dual actions of phorbol esters to decrease calcium and potassium conductances of mouse neurons. Neurosci. Lett. 78: 101-106.

Zurgil, N., M. Yarom, and N. Zisapel (1986) Concerted enhancement of calcium influx, neurotransmitter release and protein phosphorylation by a phorbol ester in cultured brain neurons. Neuroscience 19: 1255-1264. 